\title{
PROPAGAÇÃO VEGETATIVA DE Platanus acerifolia Ait.: (I) EFEITO DE TIPOS FISIOLÓGICOS DAS ESTACAS E ÉPOCAS DE COLETA NO ENRAIZAMENTO DE ESTACAS ${ }^{1}$
}

\author{
VEGETATIVE PROPAGATION OF Platanus acerifolia Ait.: (I) EFFECT OF PHYSIOLOGICAL \\ TYPES OF CUTTINGS AND TIMES OF THE CUTTINGS COLLECTION ON ROOTING
}

\author{
Fernando Teixeira Nicoloso ${ }^{2}$ Marcondes Lazzari $^{3}$ Roni Paulo Fortunato ${ }^{4}$
}

RESUMO

O objetivo desse trabalho foi avaliar os efeitos do tipo fisiológico da estaca e da época de coleta no enraizamento de estacas de Platanus acerifolia Ait. Os tratamentos consistiram de uma combinação bifatorial (4 $x 4$ ), representados por quatro tipos fisiológicos de estacas de ramos ("de ano", "do ano" basal, "do ano" mediana e "do ano" basal fina) e quatro épocas de coleta (setembro/95, janeiro/96, março/96 e julho/96). A estaquia foi realizada em vasos contendo como substrato uma mistura de areia média e casca de arroz carbonizada (1:1, v/v), ambas lavadas. $O$ experimento foi conduzido por 110 dias em casa de vegetação com sistema de microaspersão intermitente. A melhor época de coleta das estacas para o enraizamento é em julho e as estacas de ramos "do ano" basais apresentam o maior potencial de enraizamento.

Palavras-chave: propagação vegetativa, Platanus acerifolia tipos de estacas, época de coleta, enraizamento.

\section{SUMMARY}

The aim of this work was to evaluate the effect of the physiological type of the cutting on rooting of Platanus acerifolia Ait. cuttings collected at different times. The treatments followed a $4 \times 4$ factorial scheme, involving four physiological types of the cuttings (hardwood, basal semi-herbaceous, middle semiherbaceous, and thin basal semi-herbaceous), and four different times of the cuttings collection (September/95, January/96, March/96, and July/96). The cuttings were rooted in pots containing as substrate a mixture of medium sand + carbonised rice husk, 1:1 v/v, both washed. The experiment was conducted during 110 days under intermittent artificial mist conditions. The results indicate that the best time to collect cuttings to get rooting is in July, and basal semi-herbaceous cutting shows the best percentage on rooting.

Key words: vegetative propagation, Platanus acerifolia, rooting, type of cutting, cutting collection epoch.

\section{INTRODUÇÃO}

O plátano híbrido (Platanus acerifolia Ait.) é uma espécie florestal muito difundida, especialmente como árvore ornamental na arborização de ruas, parques e praças, bem como pela qualidade de sua madeira empregada na carpintaria, fabricação de móveis e pisos (LEONARDIS, 1977; MERINO, 1991; ONO et al., 1994).

As sementes de plátano são produzidas anualmente, espalhando-se irregularmente durante o inverno e início da primavera; contudo, a percentagem de germinação é pequena, determinando baixo índice de propagação (HARLOW \& HARRAR, 1969; LEONARDIS, 1977). Este fato tem determinado o uso da propagação vegetativa, principalmente via estaquia, como o método tradicional de produção de mudas dessa espécie.

A capacidade da estaca emitir raízes é uma função da interação de fatores endógenos e das condições ambientais proporcionadas ao enraiza-

${ }^{1}$ Projeto Financiado pela Fundação de Incentivo à Pesquisa e Ensino (FIPE) - Universidade Federal de Santa Maria (UFSM) \& FAPERGS.

${ }^{2}$ Engenheiro Agrônomo, PhD., Professor Adjunto do Departamento de Biologia, Centro de Ciências Naturais e Exatas (CCNE), UFSM, 97105-900, Santa Maria, RS. E-mail: nicoloso@sm.conex.com.br. Autor para correspondência.

${ }^{3}$ Engenheiro Agrônomo, Mestre em Agronomia.

${ }^{4}$ Acadêmico do Curso de Agronomia, UFSM, Bolsista da FAPERGS 
mento. Tem sido observado que a formação de raízes adventícias deve-se à interação de fatores existentes nos tecidos e da translocação de substâncias sintetizadas nas folhas e gemas em desenvolvimento. Entre estes fatores, os níveis de carboidratos, água, fito-hormônios e nutrientes minerais são de fundamental importância (WANG \& ANDERSEN, 1989; SMALLEY et al., 1991; HENRY et al., 1992; MAYNARD \& BASSUK, 1992; RIEGER, 1992; FACHINELLO et al., 1994).

O teor de carboidratos nos tecidos parece estar relacionado com a consistência das estacas, que varia durante o período anual. As estacas coletadas em um período de crescimento vegetativo intenso, primavera e verão, apresentam-se com poucas reservas de carboidratos e com consistência mais herbácea. Já estacas coletadas no inverno possuem um maior grau de lignificação e teores mais elevados de carboidratos (FACHINELLO et al., 1994). Essas observações também estão relacionadas aos níveis de fito-hormônios dos tecidos, ou seja: estacas herbáceas possuem alta concentração de auxinas e baixa concentração de substâncias inibidoras do crescimento (BARTOLINI, 1990; ELKASSAS et al., 1990; EVERT \& SMITTLE, 1990; FACHINELLO et al., 1994).

Segundo IRITANI et al. (1986), o enraizamento de estacas de Ilex paraguaiensis foi melhor para aquelas coletadas no início de outono, comparadas as de inverno. BEZERRA et al. (1992) verificaram em estacas de Malpighia glabra, coletadas em abril, maior percentual de enraizamento $(87,3 \%)$ do que as coletadas em fevereiro $(47,5 \%)$.

VLACHOV (1988), em experimento realizado no hemisfério norte, constatou que a capacidade de enraizamento de três tipos de estacas de ramos "do ano" de Platanus acerifolia, obtidas ao longo da extensão do mesmo ramo (basais, medianas e apicais), foi significativamente diferente, sendo que as basais (mais lenhosas) apresentaram potencial superior, independente da época em que foram coletadas. Contudo, ONO et al. (1994), em Botucatu SP, observaram que, para alcançar uma alta percentagem de estacas enraizadas de Platanus acerifolia, o outono foi a melhor época para retirar ramos; sendo que, neste trabalho, não houve distinção entre tipos de estacas. Considerando-se as discrepâncias existentes na literatura sobre o enraizamento de estacas de Platanus acerifolia, bem como a inexistência de dados para as condições climáticas de Santa Maria, o presente trabalho objetivou avaliar os efeitos do tipo fisiológico das estacas e de sua época de coleta no enraizamento.

\section{MATERIAL E MÉTODOS}

Este trabalho foi conduzido na Universidade Federal de Santa Maria (UFSM), Santa Maria RS. A condução do experimento foi realizada na casa de vegetação do Departamento de Ciências Florestais.

O material vegetativo utilizado no experimento proveio de cinco árvores matrizes de plátano, com idade aproximada de 30 anos, e obtidas via estaquia, localizadas próximo à UFSM. Foram utilizadas estacas com comprimento médio de $20 \mathrm{~cm}$, sem folhas, possuindo três a quatro gemas. Os tratamentos consistiram da combinação de quatro épocas de coleta e de quatro tipos fisiológicos de estacas, sendo que nem sempre todos os tipos estiveram representados nas diferentes épocas. A coleta das estacas foi realizada em quatro diferentes épocas do ano (setembro/95, janeiro/96, março/96 e julho/96 designadas, respectivamente, como época I, II, III e IV).

Os tipos fisiológicos de estacas foram obtidas de ramos "do ano" (ciclo de crescimento corrente), possuindo comprimento de 80 a $110 \mathrm{~cm}$, e de ramos "de ano" (segundo ciclo de crescimento corrente) de tamanhos variados. As estacas do tipo fisiológico "de ano" foram obtidas aleatoriamente de ramos com diversos graus de desenvolvimento, sendo que cada ramo originou várias estacas através de cortes sucessivos (método tradicional).

Com exceção da primeira época de coleta, as estacas do tipo fisiológico "do ano" foram divididas em estacas basais e medianas obtidas, respectivamente, da porção basal extrema e subseqüentemente acima dessa. Na época I, as estacas também foram obtidas destas porções, porém não se fez distinção entre as posições que ocupavam no ramo. $\mathrm{Na}$ época IV, acrescentou-se um novo tipo fisiológico de estaca denominada "do ano" basal fina, obtida da porção basal de ramos "do ano" que possuíam crescimento inferior a $70 \mathrm{~cm}$ de comprimento.

$\mathrm{Na}$ coleta das estacas, o estado fisiológico dos ramos que lhe deram origem foi avaliado pelo aspecto externo, variando de acordo com a época do ano, como segue: época I (setembro de 95): ramos com gemas em estágio de inchamento e abertura das escamas, com algumas em ínicio de brotação, evidenciando saída do estado de dormência; época II (janeiro de 96): ramos apresentavam-se em pleno crescimento vegetativo, evidenciado pela presença de folhas em mais de $90 \%$ das gemas; época III (março de 96): ramos com folhas cloróticas em graus variados e em fase de abscisão, indicando que a planta estava diminuindo as atividades metabólicas visando à entrada na fase de dormência; época IV 
(julho de 96): ramos com dormência absoluta de gemas.

O estaqueamento foi realizado em vasos plásticos, pintados externamente de cor marfim, com capacidade para 1,6 litros. Como substrato, utilizaram-se areia média de rio e casca de arroz carbonizada, ambas lavadas, na proporção de 1:1 (v/v).

A condução do experimento foi realizada em casa de vegetação, por período de 110 dias, onde, além da água fornecida por aspersão, forneceram-se $150 \mathrm{ml}$ de água/vaso diariamente, sempre que a temperatura do ar ultrapassava $25^{\circ} \mathrm{C}$. Na instalação e no decorrer do experimento, fez-se tratamento anti-fúngico das estacas com Benlate (benomyl), na dose de $0,6 \mathrm{~g} \mathrm{l}^{-1}$, a cada 2 semanas. Na época IV, os botões florais foram retirados no momento de sua emissão.

O delineamento experimental foi inteiramente casualizado com quatro repetições por tratamento, contendo cada repetição três estacas. Os parâmetros avaliados no encerramento do experimento foram: número de raízes primárias por estaca, comprimento das raízes primárias por estaca, matéria seca de raízes por estaca e percentagem de estacas enraizadas. A análise estatística foi realizada através do teste de Duncan, com significância em nível de probabilidade de erro de $5 \%$.

\section{RESULTADOS E DISCUSSÃO}

\section{a) Tipo fisiológico da estaca}

\section{Percentagem de estacas enraizadas}

$\mathrm{O}$ percentual de estacas enraizadas diferiu significativamente para o tipo fisiológico de estaca nas quatro épocas de coleta, sendo aquelas "do ano" superiores as "de ano" (Tabela 1). Este resultado pode estar relacionado ao maior conteúdo de auxinas nas estacas de ramos "do ano", que são de consistência mais herbácea.

As estacas de ramos "de ano" tiveram brotação intensa antes da formação dos primórdios radiculares, ocasionando desidratação, possivelmente, devido à maior transpiração em relação à absorção de água. Além disso, houve, possivelmente, maior consumo dos açúcares de reserva por este processo, resultando conseqüentemente num baixo percentual de enraizamento. O mesmo comportamento foi verificado por CHALFUN et al. (1990), em estacas de Hibiscus rosa-sinensis L. de flores brancas, consideradas de difícil enraizamento. FACHINELLO et al. (1994) ratificam esta observação, afirmando que, às vezes, o maior diâmetro das estacas está relacionado com mais brotações e poucas raízes.

Para estacas de ramos "do ano", observou-se que, na percentagem de enraizamento, as basais foram significativamente superiores às medianas na época III, enquanto que na época II houve uma tendência de seguir este mesmo comportamento (tabela 1). Em decorrência das estacas basais proporcionarem melhores resultados que as medianas, sugere-se que: (i) concordando com FACHINELLO et al. (1994), os maiores teores de carboidratos na base dos ramos podem contribuir para o enraizamento e sobrevivência das estacas, e (ii) o maior grau de lignificação das estacas basais proporcionou maior resistência à dessecação.

Os resultados observados quanto às diferenças no tipo fisiológico das estacas de ramo "do ano", nas épocas II e III, estão de acordo com aqueles obtidos por VLACHOV (1988). Este autor estudou o enraizamento de três tipos de estacas de Platanus acerifolia, obtidas ao longo da extensão do ramo (basais, medianas e apicais), observando que os melhores resultados foram para as estacas basais, seguidas pelas medianas. Porém, o resultado observado na época IV difere daquele constatado por VLACHOV (1988), que, independente da época de coleta dos ramos, verificou maior potencial para as estacas basais.

A ausência de diferença entre os tipos de estacas de ramos "do ano", na época IV, sugere a existência de outros fatores endógenos, além do conteúdo de carboidratos, interagindo no processo de enraizamento e, assim, dificultando uma generalização quanto à recomendação do melhor tipo fisiológico de estacas de ramos "do ano", coletadas no inverno.

\section{Crescimento do sistema radicular}

Quanto ao número de raízes primárias verificou-se diferença significativa apenas na época IV, onde as estacas de ramos "do ano" medianas e basais apresentaram-se significativamente superiores às "do ano" basais finas (tabela 1). Esses resultados estão de acordo com aqueles observados por LIMA et al. (1992) em acerola (Malpighia glabra). Estes autores verificaram que as estacas semilenhosas (diâmetro maior) apresentaram maior número de raízes por estaca do que as herbáceas (diâmetro menor).

A diferença observada na capacidade de formação de raízes adventícias em favor das estacas obtidas de ramos mais desenvolvidos deve-se, provavelmente, à maior concentração de carboidratos naquelas mais grossas (FACHINELLO et al. 1994), que proporcionaram desenvolvimento de maior número de loci meristemáticos.

$\mathrm{Na}$ época II, não se verificou diferença entre os tipos fisiológicos de estacas quanto ao comprimento de raízes primárias (tabela 1). Na época III, 
Tabela 1 - Efeito do tipo fisiológico de estacas de ramos de Platanus acerifolia Ait., coletados em quatro épocas do ano, no percentual de enraizamento, comprimento e número de raízes primárias e na matéria seca de raízes por estaca. Santa Maria, RS, 1998.

\begin{tabular}{|c|c|c|c|c|c|c|}
\hline Tipo de estaca & Épocas de coleta & $\begin{array}{l}\text { diâmetro das } \\
\text { estacas }(\mathrm{mm})^{* 1}\end{array}$ & $\begin{array}{l}\text { percentagem de } \\
\text { enraizamento }\end{array}$ & $\begin{array}{l}\mathrm{n}^{\mathrm{o}} \text { de raízes } \\
\text { primárias }\end{array}$ & $\begin{array}{l}\text { comprimento de } \\
\text { raízes primárias }(\mathrm{cm})\end{array}$ & $\begin{array}{l}\text { matéria seca de } \\
\text { raízes }(\mathrm{mg})\end{array}$ \\
\hline “de ano" $*^{2}$ & I & 10,12 & $18,0 \mathrm{~b} *^{3}$ & $38,5 \mathrm{a}$ & n.d. $*^{4}$ & $376 a$ \\
\hline "do ano" $*^{2}$ & (setembro/95) & 7,03 & $49,0 \mathrm{a}$ & $42,6 a$ & n.d. & $377 \mathrm{a}$ \\
\hline "de ano" $*^{2}$ & & 9,73 & $4,0 \mathrm{~b}$ & $31,7 \mathrm{a}$ & $6,7 \mathrm{a}$ & $140 \mathrm{~b}$ \\
\hline "do ano" basal & II & 6,42 & $30,0 \mathrm{a}$ & $41,1 \mathrm{a}$ & $8,1 \mathrm{a}$ & $372 a$ \\
\hline "do ano" mediana & (janeiro/96) & 4,64 & $19,0 \mathrm{a}$ & $25,7 \mathrm{a}$ & $9,0 \mathrm{a}$ & $259 \mathrm{ab}$ \\
\hline "de ano" $*^{2}$ & & 10,78 & $15,3 \mathrm{~b}$ & $21,6 \mathrm{a}$ & $6,4 \mathrm{a}$ & $107 \mathrm{a}$ \\
\hline "do ano" basal & III & 8,27 & $48,7 \mathrm{a}$ & $19,4 \mathrm{a}$ & $4,1 \mathrm{~b}$ & $51 \mathrm{ab}$ \\
\hline "do ano" mediana & (março/96) & 6,58 & $19,3 \mathrm{~b}$ & $10,4 \mathrm{a}$ & $4,9 \mathrm{a} \mathrm{b}$ & $28 \mathrm{~b}$ \\
\hline "do ano" basal & & 6,87 & $91,6 \mathrm{a}$ & $32,7 \mathrm{a}$ & $5,8 \mathrm{~b}$ & $219 \mathrm{a}$ \\
\hline "do ano" mediana & IV & 5,67 & $87,5 \mathrm{a}$ & $34,3 \mathrm{a}$ & $5,2 \mathrm{c}$ & $204 a$ \\
\hline "do ano" basal fina & (julho/96) & 4,33 & $87,5 \mathrm{a}$ & $24,3 \mathrm{~b}$ & $6,3 \mathrm{a}$ & $153 \mathrm{~b}$ \\
\hline C.V. & & 7,8 & 23,5 & 38,8 & 35,9 & 51,6 \\
\hline
\end{tabular}

*1 Diâmetro a $1 \mathrm{~cm}$ abaixo da primeira gema apical.

$*^{2}$ Não se fez distinção das estacas quanto à posição que ocupava no ramo.

${ }^{*}$ Médias seguidas por mesma letra, na coluna e dentro de época, não diferem entre si pelo teste de Duncan a 5\% de probabilidade.

$*^{4}$ n.d.: variável não determinada.

as estacas de ramos "de ano" apresentaram-se significativamente superiores às estacas de ramos "do ano" basais. Talvez este fato esteja relacionado à maior disponibilidade de carboidratos nos ramos de maior diâmetro (FACHINELLO et al., 1994).

Resultados contrastantes no comprimento de raízes primárias foram obtidos para estacas coletadas na época IV, onde as de ramos "do ano" basais finas foram significativamente superiores às demais. Estes resultados sugerem que, não havendo brotação na fase inicial do experimento, devido ao frio, as estacas tiveram como única fonte de carboidratos o que tinha sido armazenado até o início da fase de dormência. Assim, as estacas mais lenhosas (de ramos "do ano" basal e mediana), provavelmente com maior conteúdo de carboidratos, destinaram essas reservas para um maior número de loci meristemáticos, induzindo assim a formação de maior número de raízes primárias. Por outro lado, as estacas de ramos "do ano" basais finas, que possuíam menor conteúdo de reserva, destinaram seus carboidratos aos poucos loci meristemáticos e formando então menor número de raízes primárias. Próximo ao término do experimento, a temperatura do ar elevouse, influenciando na superação da dormência das gemas, que culminou com o desenvolvimento da brotação e, assim, contribuindo para o aumento da fotossíntese. A partir daí, começou a aumentar a disponibilidade de carboidratos e, como as estacas de ramos "do ano" basais finas formaram menor número de raízes primárias, esses fotossintatos, provavelmente, destinaram-se, em maior quantidade, às poucas raízes formadas, proporcionando seu maior crescimento. Esta hipótese baseia-se na análise de correlação entre comprimento e número de raízes (tabela 2), onde se observou relação inversa entre estas variáveis (significância a $1 \%$ e coeficiente de determinação próximo a 86\%).

A produção de matéria seca de raízes variou significativamente com o tipo fisiológico da estaca (tabela 1). Em todas as épocas de coleta, houve a tendência das estacas de maior diâmetro proporcionarem maior produção de matéria seca radicular. Isso sugere que, devido a estas estacas possuírem maior conteúdo de carboidratos de reserva (FACHINELLO et al., 1994), também ocorra a sua maior utilização na formação do sistema radicular. Estes dados concordam com aqueles observados por LIMA et al. (1992) em acerola (Malpighia glabra L.), onde estacas semilenhosas, de maior diâmetro, proporcionaram maior desenvolvimento das raízes adventícias, avaliado como produção de matéria seca, do que as estacas herbáceas. Entretanto, na época II, as estacas de ramos "de ano" apresentaramse menos aptas no desenvolvimento do sistema radicular adventício. Possivelmente, isso esteja rela- 
Tabela 2 - Efeito da época de coleta de dois tipos fisiológicos de estacas de Platanus acerifolia Ait. na percentagem de enraizamento, comprimento, número de raízes primárias e na matéria seca de raízes. Santa Maria, RS, 1998.

\begin{tabular}{|c|c|c|c|c|c|c|c|c|}
\hline \multirow[b]{2}{*}{ Época de coleta } & \multicolumn{2}{|c|}{$\begin{array}{l}\text { percentagem de } \\
\text { enraizamento }\end{array}$} & \multicolumn{2}{|c|}{$\begin{array}{l}\text { comprimento de } \\
\text { raízes primárias }(\mathrm{cm})\end{array}$} & \multicolumn{2}{|c|}{$\mathrm{n}^{\circ}$ de raízes primárias } & \multicolumn{2}{|c|}{$\begin{array}{l}\text { matéria seca de } \\
\text { raízes }(\mathrm{mg})\end{array}$} \\
\hline & "de ano" & "do ano**", & "de ano" & "do ano*" & "de ano" & "do ano*1", & "de ano" & "do ano*"," \\
\hline I (setembro/95) & $18,0 \mathrm{a}^{* 2}$ & $49,0 \mathrm{~b}$ & n.d. $*^{4}$ & n.d. & $38,5 \mathrm{a}$ & $42,6 \mathrm{a}$ & $380 \mathrm{a}$ & $380 \mathrm{a}$ \\
\hline II (janeiro/96) & $4,0 \mathrm{~b}$ & $24,5 \mathrm{c}$ & $6,7 \mathrm{a}$ & $8,5 \mathrm{a}$ & $31,7 \mathrm{a}$ & $34,5 \mathrm{~b}$ & $140 \mathrm{~b}$ & $320 \mathrm{a}$ \\
\hline III (março/96) & $15,3 \mathrm{a}$ & $34,0 \mathrm{c}$ & $6,4 \mathrm{a}$ & $4,4 \mathrm{c}$ & $21,5 \mathrm{a}$ & $16,4 \mathrm{c}$ & $110 \mathrm{~b}$ & $40 \mathrm{c}$ \\
\hline IV (julho/96) & n.t. $*^{3}$ & 89,6 a & n.t. & $5,5 \mathrm{~b}$ & n.t. & $33,5 \mathrm{~b}$ & n.t. & $210 \mathrm{~b}$ \\
\hline C.V. & 21,4 & 25,6 & 28,2 & 43,8 & 42,3 & 35,3 & 49,5 & 53,7 \\
\hline
\end{tabular}

*1 Os valores apresentados às estacas de ramos “do ano”, nas épocas II, III e IV, são a média entre os tipo basal e mediana.

$*^{2}$ Médias seguidas pela mesma letra na coluna não diferem entre si pelo teste de Duncan a $5 \%$ de probabilidade.

$*^{3}$ n.t.: tipo de estaca não testado.

${ }^{*}$ n.d.: variável não determinada.

cionado com: (i) as altas temperaturas durante o período experimental, estimulando a transpiração e (ii) ao estádio de desenvolvimento das plantas matrizes. Na época da coleta, os ramos apresentavam-se em pleno desenvolvimento vegetativo, indicando, assim, que o metabolismo nos tecidos das estacas estava direcionado para a oxidação dos fotossintatos, visando ao crescimento da planta e não em armazená-los. Além disso, como já mencionado anteriormente, as estacas de ramos "de ano" tiveram maior desenvolvimento da brotação antes da formação dos primórdios radiculares, fato que ocasionou maior desidratação, associado ao consumo dos açúcares de reserva que poderiam ter sido utilizados na formação de raízes.

\section{b) Efeito da época de coleta}

\section{Percentagem de estacas enraizadas}

Para todos os tipos de estacas estudados, verificou-se que o percentual de enraizamento foi significativamente superior na época IV (Tabela 2) em relação às demais épocas. Nesta época, as estacas ficaram submetidas a baixas temperaturas até a metade do período experimental, facilitando sua sobrevivência e posterior enraizamento; além disso, a elevação da temperatura do ar na fase final parece não ter sido prejudicial, porque as estacas não mostraram sintomas visíveis de estresse hídrico, indicando, assim, já ter desenvolvido adequadamente o sistema radicular.

O enraizamento obtido na época III foi prejudicado devido às estacas passarem todo o perí- odo experimental sob baixas temperaturas, o que fez com que parte delas permanecesse viva, mas sem enraizar, diferente da época IV que teve elevação das temperaturas no final do experimento.

A menor percentagem de enraizamento foi obtida na época II (janeiro). Este resultado parece estar relacionado à alta temperatura do ar existente durante este período experimental que deve ter provocado grande transpiração. Cabe ressaltar que o sistema de aspersão utilizado não controlou satisfatoriamente a elevação da temperatura do ar.

Segundo VLACHOV (1988), estacas de três espécies do gênero Platanus com gemas floríferas ou coletadas durante a floração tenderam a enraizar menos que aquelas provenientes de ramos vegetativos em fase de crescimento ativo, o que mostra um antagonismo entre floração e o enraizamento. Com base nos relatos de CHIN et al. (1969) e HAISING (1972), altos níveis de ácido giberélico (GA) endógeno bloqueiam a atividade auxínica sobre o desenvolvimento dos primórdios radiculares e, em conseqüência, a formação de raízes. ONO $\boldsymbol{e t}$ al. (1994) sugerem que o baixo percentual de enraizamento de ramos de Platanus acerifolia coletados na primavera foi ocasionado por altos níveis de GA, sendo que o inverso teria ocorrido no outono, onde os níveis de GA estariam baixos. Estes resultados diferem dos observados neste trabalho, que mostraram maior percentual de enraizamento naquelas estacas com formação de botões florais.

\section{Crescimento do Sistema radicular}

O número de raízes primárias por estaca pode estar ligado ao teor endógeno de ácido indola- 
cético (AIA), considerando-se que uma das funções deste fito-hormônio, segundo BLAKESLEY et al. (1990), é de induzir a formação de loci meristemáticos na base da estaca. De acordo com TAIZ \& ZEIGER (1991), a mais alta taxa de síntese de AIA, principal auxina nas plantas, ocorre nos pontos de crescimento da parte aérea (gemas e folhas jovens). Portanto, nas épocas I e II, respectivamente, correspondentes à primavera e ao verão, a produção desse fito-hormônio é maior, justificando a tendência do maior número de raízes observados nas estacas coletadas nessas épocas (tabela 2).

$\mathrm{O}$ baixo número de raízes em estacas da época III está, possivelmente, associado com: (i) a ausência de brotação devido à temperatura baixa durante o período experimental e (ii) o alto teor de inibidores, comuns na fase de dormência.

O comprimento de raízes primárias foi avaliado apenas nas épocas II, III e IV. O maior valor observado foi na época II (janeiro), onde a temperatura do ar influenciou positivamente o desenvolvimento do sistema radicular (tabela 2). ONO et al. (1994) observaram que o comprimento de raízes das estaca de Platanus acerifolia, em três épocas, foi significativamente melhor na primavera que no verão e no outono.

A produção de matéria seca de raízes por estaca seguiu a mesma tendência dos outros parâmetros radiculares avaliados, ou seja: apresentou maior valor naquelas estacas coletadas na primavera/verão, épocas I e II (Tabela 2).

A alta taxa de transpiração, induzida pela temperatura do ar, parece ser o principal fator inconveniente durante o processo de enraizamento das estacas, nas estações de rápido crescimento vegetativo, avaliando-se pela percentagem de enraizamento (Tabela 2). HOFFMANN et al. (1995), estudando estacas de mirtilo (Vaccinium ashei Reade) em três épocas, ratificam este resultado. Estes autores observaram que as estacas coletadas no mês de novembro foram significativamente superiores na produção de matéria seca de raízes do que aquelas de março e de agosto.

\section{CONCLUSÃO}

O maior percentual de enraizamento é obtido por estacas de ramos "do ano" basais. A melhor época de coleta das estacas de ramos para o enraizamento é em julho.

\section{REFERÊNCIAS BIBLIOGRÁFICAS}

BARTOLINI, G.O. Improving rooting and survival of hardwood peach cutting. In: XXIII INTERNATIONAL HORTICULTURAL CONGRESS, 1990, Firenze, Italy. Anais... Bolonha: Tecnoprint, 1990, 4410 p., p. 190
BEZERRA, J.E.F, LEDERMAN, I.E, SILVA, M.F.F, $\boldsymbol{e t}$ al. Enraizamento de estacas herbáceas de acerola (Malpighia glabra L.) com ácido indol-butírico e ácido alfa-naftaleno acético a baixas concentrações em duas épocas. Revista Brasileira de Fruticultura, Cruz das Almas, v. 45, n. 1, p. 16, 1992.

BLAKESLEY, D., WESTON, G.D., HALL, J.F. The role of endogenous auxin in root initiation. Plant Growth Regulation, Netherlands, v. 10, p. 341-353, 1991.

CHALFUN, N.N.J., LOPES, L.C., TELES, F.F.F., et al. Comportamento de açúcares, aminoácidos e etileno no enraizamento de estacas de Hibiscus rosa-sinensis L. Ciência \& Prática, Lavras, v. 14, n. 2, p. 146-157, 1990

CHIN, T.Y., MEYER, J.M.M, BEEVERS, L. Abscisic acid simulated rooting of stem cuttings. Planta, New York, v. 88 p. $192-196,1969$

ELKASSAS, S.E., ELAGAMY, S.Z., ELSESE, A.M Physiological studies on rooting ability of "Sultani" and "Abiad Asswan" fig cuttings. In: XXIII INTERNATIONAL HORTICULTURAL CONGRESS, 1990, Firenze, Italy. Anais ... Bolonha: Tecnoprint, 1990, 4410 p., p.189.

EVERT, D., SMITTLE, D. Carbohydrates and survival in peach cuttings when field-rooted during mild winters. In: XXIII INTERNATIONAL HORTICULTURAL CONGRESS, 1990, Firenze, Italy. Anais ... Bolonha: Tecnoprint, 1990, 4410 p., p. 187.

FACHINELLO, J.C., HOFFMAN, A., NACHTIGAL, J.C., et al. Propagação de plantas frutíferas de clima temperado. Pelotas: UFPEL, 1994. 179 p.

HAISING, B.E. Meristematic activity during adventitious root primordium development. Influences of endogenous auxin and applied gibberellic acid. Plant Physiology, Bethesda, v. 49, p. 886-892, 1972.

HARLOW, W.M. HARRAR, E.S. Textbook of dendrology. New York. McGraw-Hill, Inc., 1969. 775 p.

HENRY, P.A., BLAZICH, F.A., HINESLEY, L.E. Influence of stock fertility on adventicious rooting of stem cuttings. Journal of American Society Horticulture Science, Alexandria, v. 117, p. 568-570, 1992.

HOFFMANN, A., FACHINELLO, J.C., SANTOS, A.M Propagação de mirtilo (Vaccinium ashei Reade) através de estacas. Pesquisa Agropecuária Brasileira, Brasília, v. 30, n. 2, p. 231-236, 1995.

IRITANI, C., SOARES, R.V., GOMES, A.V. Aspectos morfológicos da aplicação de reguladores do crescimento nas estacas de Ilex paraguariensis St. Hilaire. Acta Biológica Paranaense, Curitiba, n. 1-4, v. 15, p. 21-26, 1986.

LEONARDIS, R.F.J. Libro del Arbol: Esencias florestales no autóctonas cultivadas en la Argentina de aplicacion ornamental y/o industrial. Buenos Aires: Celulosa Argentina, 1977. V. 3. 355 p.

LIMA, A.C.S., ALMEIDA, F.A.C., ALMEIDA, F.C.G. Estudo sobre o enraizamento de estacas de acerola (Malpighia glabra L.). Revista Brasileira de Fruticultura, Cruz das Almas, v. 14, n. 1, p. 7-13, 1992. 
MAYNARD, B.K., BASSUK, N.L. Stock plant etiolation, shading, and banding effects on cutting propagation of Carpinus betulus. Journal of American Society Horticulture Science, Alexandria, v. 117, n. 5, p. 740-744, 1992.

MERINO, D.M. Cortavientos en agricultura. Madrid: Mundi, $1991.79 \mathrm{p}$

ONO, E.O., DE BARROS, S.A., RODRIGUES, J.D., et al. Enraizamento de estacas de Platanus acerifolia, tratadas com auxinas. Pesquisa Agropecuária Brasileira, Brasília, v. 29, n. 9 , p. $1373-1380,1994$.

RIEGER, M. Growth, gas exchange, water uptake, and drought response of seedling- and cutting- propagate peach and citrus rootstock. Journal of American Society Horticulture Science, Alexandria, v. 117, n. 5, p. 834-840, 1992.
SMALlEY, T.J, DIR, M.A., ARMITAGE, A.M., $\boldsymbol{e}$ t al. Photosynthesis and leaf water carbohydrate and hormone status during rooting of stem cuttings of Acer rubrum. Journal of American Society Horticulture Science, Alexandria, v. 116, p. 1052-1057, 1991.

TAIZ, L., ZEIGER, E. Plant Physiology. New York: The Benjamin / Cummings, 1991. 486 p.

VLACHOV, D.D. Vegetative propagation of sp. Platanus L. through rooting of cuttings. Acta Horticulturae, Wageningen, v. 226, p. 375-378, 1988.

WANG, Q., ANDERSEN, A.S. Propagation of Hibiscus rosasinensis: relations between stock plant cultivar, age, environment and growth regulator treatments. Acta Horticulturae, Wageningen, v. 245, p. 289-309, 1989.

Ciência Rural, v. 29, n. 3, 1999. 